\title{
OPTIMAL MAP CONIC PROJECTION - A CASE STUDY FOR THE GEOGRAPHIC TERRITORY OF SERBIA
}

\author{
Mirko Borisov, Vladimir M. Petrović, Milivoj Vulić
}

Original scientific paper

The article deals with finding the optimal map conic projection which, according to the criteria of the minimum of distortions, would be more appropriate than the available and, up to the present point in time, generally used conic map projections. Apart from the best map projection, the paper also describes other conic projections still used in the official cartography of Serbia. In the paper, the size of the deformations is analysed and shown in case of the Modified polyconic projection and the Lambert conic projection on the example of a geographical map at scale 1:1000 000. Namely, the size of the linear deformations is analysed and shown in all cases. One of them, the fifth example of the Lambert conformal conic projection, is the most favourable in terms of size and distribution of the deformations upon the entire surface of mapping. Examples of real conformal conic projections are made with numerical procedures in the program package MATLAB.

Keywords: geodesy; map conic projection; mathematical cartography; minimum deformation; optimisation

Optimalna kartografska konična projekcija - analiza slučaja za geografski teritorij Srbije

Izvorni znanstveni članak

Rad se bavi pronalaženjem optimalne kartografske konične projekcije koja bi, u skladu s kriterijima minimalnih distorzija, bila prihvatljivija od postojećih i do sada općenito korištenih koničnih kartografskih projekcija. Osim najbolje kartografske projekcije, u radu se također opisuju druge konične projekcije koje se još uvijek rabe u službenoj kartografiji Srbije. U radu se veličina deformacija analizira i prikazuje u slučaju Modificirane višekonične projekcije i Lambertove konične projekcije na primjeru geografske karte u omjeru 1:1000 000. Naime, veličina linearnih deformacija analizira se i prikazuje u svim slučajevima. Jedan od njih, peti primjer Lambertove konformne konične projekcije, najpogodniji je u odnosu na veličinu i distribuciju deformacija na cijeloj površini kartiranja (mapiranja). Primjeri stvarnih konformnih koničnih projekcija napravljeni su primjenom numeričkih postupaka programskog paketa MATLAB.

Ključne riječi: geodezija; kartografska konična projekcija; matematička kartografija; minimalna deformacija; optimizacija

\section{Introduction}

In geodesy and mathematical cartography, there are different rules of mapping (means of projecting) of the curved surface of the Earth's ellipsoid or sphere onto a straight surface or onto any other surface that may be developed into a plane [1]. In much of official cartography in the world, two groups of map projections are most frequently applied. The first group consists of cylindrical and the second of conical map projections [2]. Cylindrical map projections are more frequently used for land surveying and mapping at larger scales (as in the case of topographic maps) and conical projections for geographic maps at a smaller scale (as in the case of overviewing topographic and aviatory maps).

Serbia and some countries that had previously made up a country along with it used, and still use, a set of conical projections in their official cartography. These are primarily real conical and polyconical projections with certain conditions for mapping or for the modification of linear (deformation) scales. Particularly interesting is the real conic conformal projection of the geographic maps at scales 1:500 000 and 1:1000 000 [3]. Conic conformal projections are important as pertaining to navigation in aircraft as well as other interests. The importance of their use comes from the fact that in conformal projections the linear scale in a point does not depend on its azimuth, unlike in all non-conformal map projections in which the linear scale depends on the position of the point as well as the direction of the observation (azimuth) of a point. In this sense, the analysis of linear deformations in conformal projections is simpler than in any other nonconformal projections [4].
This paper presents the best conic projection with the minimum absolute linear deformation and its symmetrical layout. Namely, the focus of this paper is on the optimisation of conic map projections. The goal is to obtain the best possible conic conformal projection fit for mapping the geographical territory of Serbia at small scales. In other words, it is a research into a more appropriate conformal conic projection, with a minimal linear deformation, while taking into account the weaknesses of conic map projections and the application of wrong mapping (the territory of mapping, variants of the projections, deformations etc).

\section{An overview of applied map conical projections up to this point in time}

Generally, when we talk about conformal mapping in geodesy and cartography, it is inevitable to mention J. H. Lambert, who in an analytical and geographically preferred way, solved the problem of mapping a sphere or an ellipsoid onto a plane [5]. Before Lambert's contributions, the only known conformal map projections were the normal (upright) conformal cylindrical projection (the Mercator projection) and the stereographic conformal projection of a sphere. Lambert, basing his process on differential equations of mapping one surface to another, found a much larger number of map projections, but as he himself surmised, solving a generally set task leads to an infinite number of different map projections [6].

In the official cartography of Serbia (and of its former states), the Lambert conformal conic projection with standard parallels $\varphi_{1}=38^{\circ} 30^{\prime}$ and $\varphi_{2}=49^{\circ} 00^{\prime}$ for a 
geographic territory of mapping (Fig. 1) was used, as it is used today [7]. It is used in producing aviatory, relief, traffic and overview topographic maps at scale 1:500 000, as well as other maps. In fact, in spite of certain weaknesses (a lower quality), with the third variant of the
Lambert conformal conic projection, as compared to the fourth and fifth variant [3], there is a lesser problem with applying the same parameters of cartographic mapping onto a different geographic territory (Fig. 1).

\section{OVERVIEW TOPOGRAPHIC MAP 1:500 000 (OTM500-SFRY)}

\section{OVERVIEW TOPOGRAPHIC MAP 1:500 000 (OTM500)}

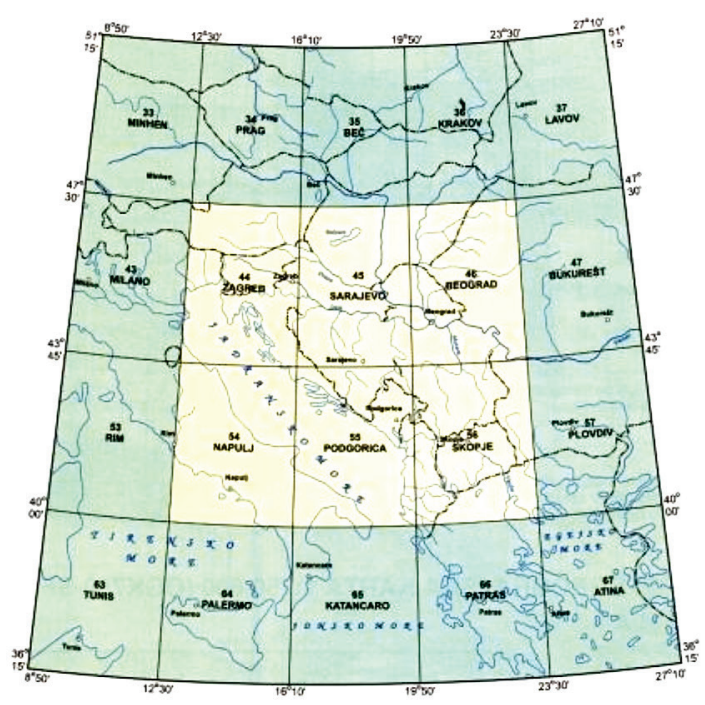

LEGEND

Contents of map sheets is from:

1978 - 1980. year

1989. year - first updated edition

\begin{tabular}{|c|c|c|c|c|c|c|}
\hline \multirow[b]{2}{*}{ Projection } & \multirow[b]{2}{*}{\begin{tabular}{|l}
$\begin{array}{l}\text { Number } \\
\text { of sheets }\end{array}$ \\
\end{tabular}} & \multirow[b]{2}{*}{$\begin{array}{c}\text { Map format } \\
\varphi \times \lambda\end{array}$} & \multirow{2}{*}{$\begin{array}{l}\text { Map sheet } \\
\text { dimension }\end{array}$} & \multirow{2}{*}{$\begin{array}{l}\text { Covered } \\
\text { map area }\end{array}$} & \multicolumn{2}{|c|}{ Variants of editions } \\
\hline & & & & & $\begin{array}{c}\begin{array}{c}\text { analogue } \\
\text { shape }\end{array} \\
\end{array}$ & $\begin{array}{l}\text { digital } \\
\text { shape }\end{array}$ \\
\hline $\begin{array}{c}\text { Lambert } \\
\text { conformal } \\
\text { conic with } \\
\text { wo standard } \\
\text { parallel }\end{array}$ & 20 & $3^{\circ} 40^{\circ} \times 3^{\circ} 45^{\circ}$ & $70 \times 100 \mathrm{~cm}$ & $120000 \mathrm{~km}$ & $\begin{array}{l}\text { - all elements } \\
\text { - pallid print } \\
\text { - pallid print } \\
\text { with } \\
\text { administrative } \\
\text { borders }\end{array}$ & $\begin{array}{l}\text { - raster (all } \\
\text { elements) }\end{array}$ \\
\hline
\end{tabular}

Figure 1 A proof sheet of the overview topographic map at scale 1:500 000 [7]

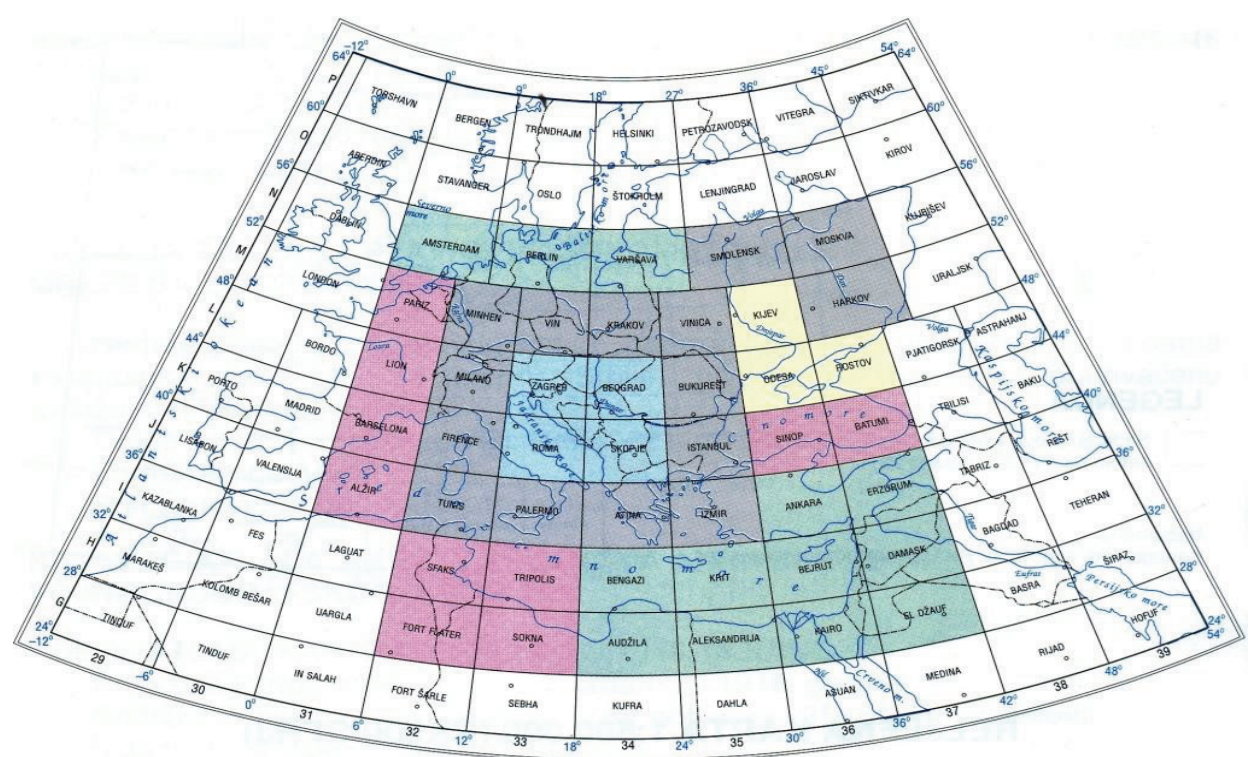

Figure 2 A proof sheet of the International map of the world at scale 1:1000 000 [7]

Apart from the Lambert conformal conic projection, there are other conic projections being used in the official cartography of Serbia [3]. Of particular interest is the

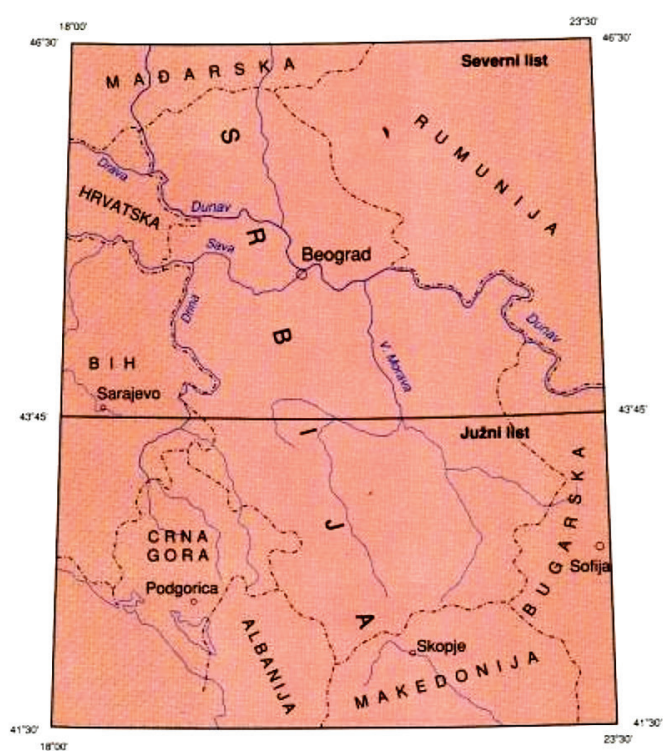

\section{LEGEND}

Contents of map sheets

is from:

1995. year

\begin{tabular}{|c|c|c|c|c|c|c|}
\hline \multirow[b]{2}{*}{ Projection } & \multirow[b]{2}{*}{$\begin{array}{l}\text { Number } \\
\text { of sheets }\end{array}$} & \multirow[b]{2}{*}{$\begin{array}{l}\text { Map format } \\
\varphi \times \wedge\end{array}$} & \multirow[b]{2}{*}{$\begin{array}{l}\text { Map sheet } \\
\text { dimension }\end{array}$} & \multirow[b]{2}{*}{$\begin{array}{c}\text { Covered } \\
\text { map area }\end{array}$} & \multicolumn{2}{|c|}{ Variants of editions } \\
\hline & & & & & $\begin{array}{c}\text { analogue } \\
\text { shape }\end{array}$ & $\begin{array}{l}\text { digital } \\
\text { shape }\end{array}$ \\
\hline $\begin{array}{c}\text { Lambert } \\
\text { conformal } \\
\text { conic with } \\
\text { two standard } \\
\text { parallel }\end{array}$ & 2 & $51^{\circ} 30^{\circ} \times 5^{\circ}$ & $92 \times 128 \mathrm{~cm}$ & $248000 \mathrm{~km}^{3}$ & 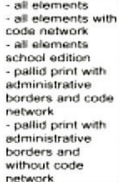 & $\begin{array}{l}\text { - raster (all } \\
\text { elements) } \\
\text { - raster (by } \\
\text { layers) }\end{array}$ \\
\hline
\end{tabular}

cork code 
mind that a geographic map in this scale held, and still holds, a great significance for the global mapping of the world as evidenced in Global Map Level 0. In the mapping of the USA, UK, Australia, it is clear that the conic projection holds great importance for mapping at small scales all over the world [9].

We also have to keep in mind that the Lambert conformal conic projection with two standard parallels has been used as the mathematical basis for surveying and mapping of the USA since 1936 [6]. That map projection is recommended for application usually in countries that have a predominantly geographic extent of territory along the parallels (Canada, USA, Russia, Turkey, China etc.). The application of the Lambert projection is suitable in the area between $84^{\circ}$ north latitude and $80^{\circ}$ south latitude. For maps of Polar Regions, i.e. regions that are north of $84^{\circ}$ and south of $80^{\circ}$, the use of the polar stereographic projection is instead advised [6].

For example, the international aviation map at scale 1:000 000, with a similar distribution on sheets is also made with the aid of the Lambert conformal conic projection and the polar stereographic projection, which has lead to a more efficient use of these very important map products of international character.

Of the other conic projections in official cartography of Serbia, the application of polyconic map projections at scale 1:750 000 and 1:1500 000 ought to be mentioned [3]. Also, in the official cartography of some countries (France, Romania, etc.), the equivalent Bonne pseudoconic projection is often applied. It is most commonly used in the preparation of thematic maps or for the needs of maps published in an atlas [10].

\section{Work methodology and selection of the best conformal conic projection}

The choice of a map projection and in general also a mathematical basis for the map is a very important issue that needs to be thought about and addressed from different viewpoints. The map projection has a special significance in the making and application of geographic maps. For instance, with different map projections, there are certain differences in the elements contained (such as image-strain data and cartographic continuity with the rest of the maps), which is a consequence of the use of different projection models and positions, and the shape of the geographic territory being mapped [11].

Because of the inevitable deformations that accompany every mapping of a curved surface onto a plane, the main scale does not change only at the points outlining the images where there is no deformation in length. At other points and in other directions on the map, the main scale cannot be preserved, so smaller and larger deviations from the imagined reduction ratio appear. Thus, the main scale only expresses the desired and optimal reduction ratio. Really, there exists the presence of deformations differing in size and in places on the map in the variability of proportions not only from point to point, but also in different directions around a point [12].

Quality changes of elements from the original surface are made in the process of mapping and are contained in its presentation on the projected surface, where they are known as deformations and are an inevitable part of all mapping. One of the main reasons for this is their size. In surface mapping theory and mathematical cartography, we operate with the notion of scales of mapping or, simply, size, invoking the relationship between each line element and its projection and original surface, as expressed by the equation [13]:

$c=\frac{\mathrm{d} S}{\mathrm{~d} s}$,

where $\mathrm{d} s$ is the differential line element of the curve (ellipsoid) on the original surface and $\mathrm{d} S$ is its image on the projected plane. Also, the steady reduction ratio is denoted as:

$R=1: M=\frac{1}{M}$

and called the main (general) map scale or, simply, the map scale and is usually noticeably printed on the sheet of geographical map. The main scale is one of the basic mathematical elements of maps and affects the quality of its workmanship [13]. It should be noted that the main scale also expresses the relationship between the decreasing of the linear elements (length), hence the name "scale of linear elements". The main scale also determines the ratio of the reducing of the surfaces and expresses the square of corresponding linear elements, i.e.: $R^{2}$.

The variance in scales is the main drawback of the map. Namely, some parts on the map are a more accurate, and some a less accurate portrayal of the Earth's surface, meaning that the quality of the map and projections can be evaluated on the basis of, among other things, the order of sizes reaching up to the changes in linear proportions. It would be, therefore, very desirable to dispose of their amounts so that the value of linear proportions for the desired point and direction can be calculated through the use of appropriate formulas [13]. Proceeding from this, the linear deformation or the deformation (distortion) of length $\left(d_{c}\right)$ would be considered the deviation of the scale $c$ from the unit, i.e.:

$d_{c}=c-1$.

The deformation of the lengths can be greater than zero, equal to zero or smaller than zero, depending on the linear scale at a given point. If we take the value of $c$ in (1) and place it in (3), we obtain:

$d_{c}=\frac{\mathrm{d} S}{\mathrm{~d} s}-1=\frac{\mathrm{d} S-\mathrm{d} s}{\mathrm{~d} s}$.

The numerator in this expression is the absolute deformation of length and the expression as a whole is an unnamed number, with which we express the relation of the whole deformation to the respect length, from where $d_{c}$ is named the relative deformation [13]. We must also point out that the deformations of lengths usually do not exceed the limit of errors of measuring on a map, so in the use of maps in practice, we disregard them, unless we are dealing with a special case. This refers particularly to 
projections used in the making of large scale maps. On smaller scale maps, that capture greater parts of the Earth, there can be great deformations of length along single straight lines of the map grid.

Keeping in mind many practical needs in official cartography of small scale maps, the most commonly used projections therein are conformal conic projections. In these kinds of projections, there are no deformations of angles, i.e. the linear scales are equal in all directions. Therefore, if the equality of linear scales is provided in all points of the map, we obtain a conformal (same-angle) mapping, with which, in any point of the conformal mapping, the indicatrix is a circle, i.e. the linear scale is constant in all directions around a given point, which we can express with the relation $a=b=m=n=c$.

However, in conformal conic projections, there exist two constants or parameters of mapping $(k, K)$ which ought to be paid special attention. They ought to be determined according to specific, pre-default conditions, and given that there are several solutions (variants), the first two solutions are related to the tangent cone, and the other three to the penetrating cone [14]:

a) The first solution: the constants $k$ and $K$ are determined by the condition that the scale $\left(n_{t}\right)$, parallel to a given length $\left(\varphi_{t}\right)$, is equal to the unity and at the same time is the smallest;

b) The second solution: another requirement is added to the one from the previous solution, i.e. apart from the requirement that, parallel to the length $\varphi_{t}$, the scale has to be equal to the unity and at the same time the smallest, it is also required that the scales on the boundary parallels (mapping territory) are equal to one another $\left(n_{S}=n_{N}\right)$;

c) The third solution: the constants of mapping are determined by the condition that scales $n_{1}$ and $n_{2}$, on two parallels of given lengths $\left(\varphi_{1}\right.$ and $\left.\varphi_{2}\right)$, are equal to the same unity $\left(n_{1}=n_{2}=1\right)$;

d) The fourth solution: the constants $k$ and $K$ are determined by the condition that the scale, on the parallel of a given length $\left(\varphi_{1}\right)$, is equal to the unity $\left(n_{1}=1\right)$, and the scales $n_{S}$ and $n_{N}$, on the boundary parallels of the territory being mapped, with parallel arcs $\varphi_{S}$ and $\varphi_{N}$, are equal $\left(n_{S}=n_{N}\right)$; and

e) The fifth solution: the constants (parameters) of the projection $k$ and $K$ are determined by the condition that the scales along the boundary parallels are equal, and that the greatest scale is greater than the unity and the smallest scale smaller than the unity.

All these variants of conformal conic map projections meet the general condition in the case of conic projections of which the following is true: $0<k<1$.

\subsection{The Lambert conformal map projection with two standard parallels - the fifth variant}

We have already emphasised the importance that the works of the German scientist H. J. Lambert had on the development of conic projections as a whole, especially on groups of conformal map projections. The sizes of the deformations, as well as their symmetry, give us a special reason for choosing the fifth variant of the Lambert projection. Here, the linear scales are symmetrically placed in both directions. The amplitudes of the linear modules are smaller than in the others, which carries the consequence of smaller surface deformations. The meridians are mapped as straight lines and converge to a single point i.e. the top of cone. For the same differences in geographic length $(\Delta \lambda)$, the meridians' convergence angles are equal. The parallels are concentric circles, and their centre is located at the top of the cone (Fig. 4). The latter is actually a Lambert projection with two standard parallels, its elements being [14]:

- $\varphi_{N}, \varphi_{S}$ - parallel arcs of the mapping territory;

- $\varphi_{1}, \varphi_{2}$ - parallel arcs being mapped without deformations (standard);

- $\quad \rho_{N}, \rho_{S}, \rho_{1}, \rho_{2}, \rho$ - radii of arcs corresponding to the parallels in the projection;

- $\quad \lambda_{0}$ - the length of the middle meridian on the mapping territory;

- $\quad \delta$ - the angle between meridians in the projection; and

- $\quad x, y$ - rectangular coordinates.

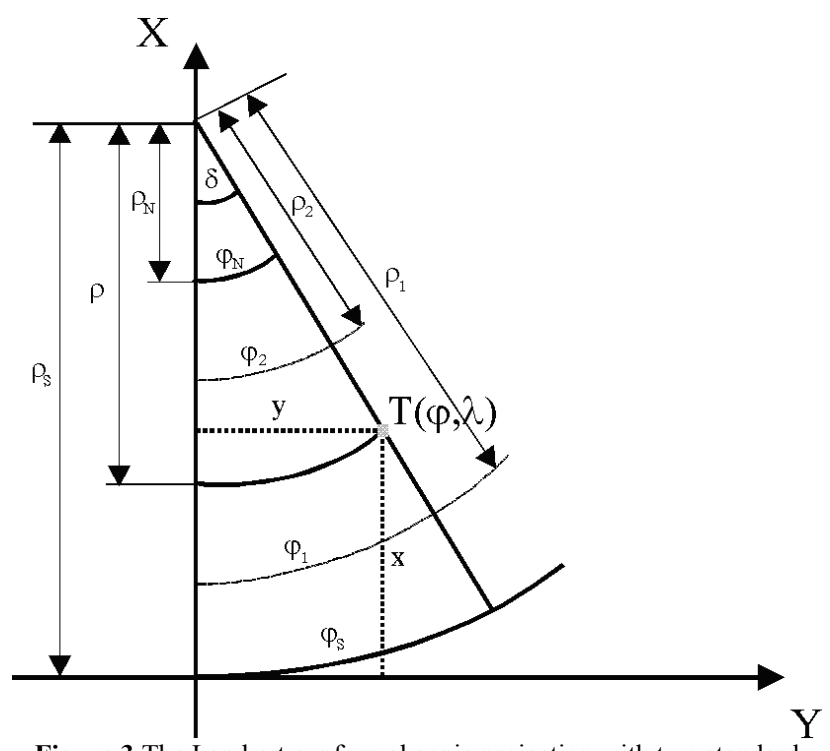

Figure 3 The Lambert conformal conic projection with two standard parallels

The relationship between polar and rectangular coordinates is determined by the following equations:

$$
\begin{aligned}
& x=\rho_{S}-\rho \cdot \cos \delta \\
& y=\rho \cdot \sin \delta
\end{aligned}
$$

Between the geographical coordinates $(\varphi, \lambda)$ of the arbitrary point $\mathrm{T}$ on the ellipsoid and its polar coordinates $(\rho, \delta)$ on the plane of the projection, there is the relation:

$$
\begin{aligned}
& \delta=k \cdot \Delta \lambda=k \cdot\left(\lambda-\lambda_{0}\right) \\
& \rho=f(\varphi)
\end{aligned}
$$

where $k$ is the proportion factor and is constant for the chosen mapping conditions. The mathematical shape of the function " $f$ " in the equation: $\rho=f(\varphi)$, depends on the determined mapping conditions. In real conformal conic projections the shape of the function " $f$ " is determined by the general conformal mapping conditions: $m=n=a=b$ $=c$ and $\omega=0$, where: $m, n, a, b$ and $c$ are labels for linear scales in corresponding directions, and $\omega$ for angle deformations. 
The expressions used for calculating the linear scale in the direction of the meridian and parallel are as follows:

$$
\begin{aligned}
& m=-\frac{1}{M} \frac{\mathrm{d} \rho}{\mathrm{d} \varphi} \\
& n=\frac{\delta \cdot \rho}{\lambda \cdot r}=k \frac{\rho}{r}
\end{aligned}
$$

where: $M$ - the radius of the curve of the meridian; $r$ - the radius of the parallel; $N$ - the radius of the curve of the first vertical.

From the condition of conformity of $m=n$, equality follows as:

$$
-\frac{1}{M} \frac{\mathrm{d} \rho}{\mathrm{d} \varphi}=k \frac{\rho}{r}
$$

from which we can determine that: $\rho=f(\varphi)$. By further rearranging the equality, we obtain the expression:

$-\frac{\mathrm{d} \rho}{\rho}=k \frac{M \cdot \mathrm{d} \varphi}{N \cdot \cos \varphi}=k \frac{\left(1-\mathrm{e}^{2}\right)}{\left(1-\mathrm{e}^{2} \cdot \sin ^{2} \varphi\right)} \cdot \frac{\mathrm{d} \varphi}{\cos \varphi}$,

from which we then obtain the expression:

$$
\int \frac{\mathrm{d} \rho}{\rho}=-k \int \frac{\left(1-\mathrm{e}^{2}\right)}{\left(1-\mathrm{e}^{2} \cdot \sin ^{2} \varphi\right)} \cdot \frac{\mathrm{d} \varphi}{\cos \varphi} .
$$

Following the integration of the given equation, we then obtain:

$$
\begin{aligned}
& \ln \rho=-k \cdot \ln \left(\tan 45^{\circ}+\frac{\varphi}{2}\right)+k \cdot \mathrm{e} \cdot \ln \left(\tan 45^{\circ}+\frac{\psi}{2}\right)+\ln K \\
& \rho=K \frac{\tan ^{k \mathrm{k}}\left(45^{\circ}+\frac{\psi}{2}\right)}{\tan ^{k}\left(45^{\circ}+\frac{\varphi}{2}\right)},
\end{aligned}
$$

where $K$ is the integrated constant which for $\varphi=0$ becomes the radius of the equator in the projection, and $\psi$ becomes the function of length that we obtain from the following equation:

$\sin \psi=\mathrm{e} \cdot \sin \varphi$

By introducing the variable:

$$
U=\frac{\tan \left(45^{\circ}+\frac{\varphi}{2}\right)}{\tan ^{\mathrm{e}}\left(45^{\circ}+\frac{\psi}{2}\right)}
$$

we obtain:

$$
\rho=\frac{K}{U^{k}}
$$

If $\varphi=0$, then on the basis of the Eq. (5) $\psi=0, U=1$ and $K=\rho$. Namely, the final equation needed for calculating the linear scales is:

$c=m=n=k \frac{\rho}{r}=\frac{k \cdot K}{r \cdot U^{k}}$.

The change of the module " $c$ " depends only on geographic width $(\varphi)$. The width of the parallel with the smallest linear scale is obtained with the derivation of the equation:

$c=k \frac{\rho}{r}$ with $\varphi$, so it is: $\frac{\mathrm{d} c}{\mathrm{~d} \varphi}=\frac{k}{r^{2}}\left(r \frac{d \rho}{\mathrm{d} \varphi}-\rho \frac{\mathrm{d} r}{\mathrm{~d} \varphi}\right)$.

By further rearranging the equation, we obtain:

$\frac{\mathrm{d} c}{\mathrm{~d} \varphi}=\frac{k \cdot M \cdot \rho}{r^{2}}(\sin \varphi-k)$

The value of the derivative equals zero when:

$$
(\sin \varphi-k)=0
$$

and if with $\varphi_{0}$ we mark the geographic width of the parallel with the smallest linear scale, we then obtain:

$\sin \varphi_{0}=k$

The second derivative " $c$ " with $\varphi$ for the value $\varphi_{0}$ is:

$\frac{\mathrm{d}^{2} c}{\mathrm{~d} \varphi^{2}}=c_{0} \frac{\left(1-\mathrm{e}^{2}\right)}{\left(1-\mathrm{e}^{2} \cdot \sin ^{2} \varphi\right)}>0$

which means that $\varphi_{0}$ is the width on which the linear scale $c_{0}$ is the smallest.

The constant projections $k$ and $K$ are determined if the scales of the length of boundary parallels are equal to one another, and if the greatest scale is greater than the unit as much as the smallest scale is smaller than the unit. Following this, the elements for the mapping of the geographical territory of Serbia may easily be calculated. By setting the conditions that:

$c_{N}=c_{S}$

and following the equations:

$\frac{k \cdot K}{U_{N}^{k} \cdot r_{N}}=\frac{k \cdot K}{U_{S}^{k} \cdot r_{S}}$

from which we obtain:

$U_{N}^{k} \cdot r_{N}=U_{S}^{k} \cdot r_{S}$ 
and then obtain:

$k=\frac{\log r_{S}-\log r_{N}}{\log U_{N}-\log U_{S}}$

where $r_{S}$ and $r_{N}$ are the radii of the boundary parallels on an ellipsoid. They are calculated with the aid of the following equations:

$r_{S}=N_{S} \cdot \cos \varphi_{S}$

$r_{N}=N_{N} \cdot \cos \varphi_{N}$

The second condition refers to the parallels $\varphi_{N}$ and $\varphi_{S}$, where the sum of the linear scales is the greatest and can be written as:

$$
\frac{k \cdot K}{U_{N}^{k} \cdot r_{N}}=\frac{k \cdot K}{U_{S}^{k} \cdot r_{S}}=1+\varepsilon
$$

where $\varepsilon$ is the absolute value of the difference between the greatest and smallest scale and unit. On the parallel $\varphi_{0}$ the linear scale is the smallest:

$$
\frac{k \cdot K}{U_{0}^{k} \cdot r_{0}}=1-\varepsilon
$$

By adding the last two equations we obtain:

$$
\frac{k \cdot K}{U_{N}^{k} \cdot r_{N}}+\frac{k \cdot K}{U_{0}^{k} \cdot r_{0}}=2 \text { or } \frac{k \cdot K}{U_{S}^{k} \cdot r_{S}}+\frac{k \cdot K}{U_{0}^{k} \cdot r_{0}}=2
$$

and

$$
K=\frac{2 \cdot U_{N}^{k} \cdot r_{N} \cdot U_{0}^{k} \cdot r_{0}}{k\left(U_{0}^{k} \cdot r_{0}+U_{N}^{k} \cdot r_{N}\right)} \text { or } K=\frac{2 \cdot U_{S}^{k} \cdot r_{S} \cdot U_{0}^{k} \cdot r_{0}}{k\left(U_{0}^{k} \cdot r_{0}+U_{S}^{k} \cdot r_{S}\right)}
$$

The geographic width $\varphi_{0}$ on which the linear scale is the smallest is obtained by solving the following equation:

$\sin \varphi_{0}=k$

The geographical width of the parallels $\varphi_{1}$ and $\varphi_{2}$, on which the linear scale is equal to the unit is determined with the aid of the following equation:

$$
r \cdot U^{k}=k \cdot K
$$

The given equation is transcendent and can be solved with the method of numerical analysis, i.e. with the iteration procedure. The conceptual calculation procedure is as follows:

- The constant $k$ is determined on the Eqs. (14) and (13) for $\varphi_{N}=46^{\circ} 30^{\prime}$ and $\varphi_{S}=41^{\circ} 30^{\prime}$;

- The geographic width of the parallel $\varphi_{0}$ on which the value of the linear scale is the smallest is determined by the Eq. (12);

- $\quad$ The constant $K$ is determined from the Eqs. (15);

- The radius of the parallels in the projection for: $\varphi_{S}$, $\varphi_{S}+\Delta \varphi, \varphi_{S}+2 \Delta \varphi, \ldots, \varphi_{N}$ is determined on the basis of Eq. (10);

- The angles between meridians in the projection are determined on the basis of the formula: $\delta=k \Delta \lambda=$ $k\left(\lambda-\lambda_{0}\right)$;

- The rectangular coordinates $X$ and $Y$, for the points of the cross section of the meridians and the parallels, are determined on the basis of the e Eqs. (5);

- The value of the linear scales on the parallels is determined on the basis of Eq. (11); and

- The width of the standard parallels is determined with the aid of interpolation of the Eq. (16).

Given the current situation and how it would be possible to compare the quality of different map projections and their variants, we must apply a unique methodology and criterion. This primarily refers to the unique mapping territory presented and a unique criterion needed for assessing quality and deformations in the same scale. All calculations in such a case would be done based on parameters of the international ellipsoid (WGS84), and the geographic widths would be established based on the relationship with the Greenwich meridian.

\subsection{Comparative characteristics of mathematical elements - a case study of IMW1000}

With the intention of presenting the physical surface of the Earth, usually the figures (a sphere or kind of ellipsoid) that best approximate the Earth's surface are used. The question about which shape will be chosen in the preparation of a geographic map depends on several factors. In Table 1, the results of calculations to do with the sphere and the ellipsoid, with an arc length of $1^{\circ}$ on the $44^{\circ}$ parallel and a meridian arc length of $1^{\circ}$ between the $44^{\circ}$ and the $45^{\circ}$ parallel are presented [14].

\begin{tabular}{|c|c|} 
Table 1 The length (differences) of the arcs from $1^{\circ}$ on the sphere and ellipsoid \\
\begin{tabular}{|c|c|c|}
\hline & $\begin{array}{c}\text { Arc length of } 1^{\circ} \\
\text { on the } 44^{\circ} \text { parallel }\end{array}$ & $\begin{array}{c}\text { Meridian arc length of } 1^{\circ} \\
\text { between the } 44^{\circ} \text { and the } 45^{\circ} \text { parallel }\end{array}$ \\
\hline On the sphere & $79978,04 \mathrm{~m}$ & $111182,54 \mathrm{~m}$ \\
\hline On the Bessel ellipsoid & $80196,50 \mathrm{~m}$ & $111109,72 \mathrm{~m}$ \\
\hline Difference & $-218,46 \mathrm{~m}$ & $+72,82 \mathrm{~m}$ \\
\hline
\end{tabular}
\end{tabular}

The radius of the sphere (ball) $\mathrm{R}$ is determined with the aid of the criterion of equal ball surfaces PL and ellipsoid PE [14], i.e. PL = PE:

$$
4 \pi R^{2}=4 \pi a^{2}\left(1-\mathrm{e}^{2}\right)\left(1+\frac{2}{3} \mathrm{e}^{2}+\frac{3}{5} \mathrm{e}^{4}+\frac{4}{7} \mathrm{e}^{6}+\ldots\right)
$$

From which we obtain:

$$
R=a \sqrt{\left(1-\mathrm{e}^{2}\right)\left(1+\frac{2}{3}+\mathrm{e}^{2}+\frac{3}{5} \mathrm{e}^{4}+\frac{4}{7} \mathrm{e}^{6}+\ldots\right.}
$$


It should also be kept in mind that the accuracy of graphic (reference value) works is $0,1 \mathrm{~mm}[15,14]$, which, when presented at scale 1:1000 000, corresponds to $100 \mathrm{~m}$ in actuality. Given the differences in the length of arcs caused by the application of different geometric bodies (Tab. 1), care should be taken that, when mapping at scale of 1:1000 000 and larger, the territory should be approximated using an ellipsoid, and not a sphere.

Following research $[15,14]$, into the comparison of numerical characteristics of the mathematical basis of maps, an example test was performed at the IMW1000 Belgrade sheet. The given paper covers the territory that extends between the $44^{\text {th }}$ and $48^{\text {th }}$ north latitude parallel and the $18^{\text {th }}$ and $24^{\text {th }}$ east longitude meridian. For mapping, the Lambert conformal conic projection and the modified polyconic projection as well as the International ellipsoid, were chosen as the most frequently used mathematical elements in official cartography.

Based on the mapping Eqs. [14] and using the parameters of WGS84, an algorithm was created in MATLAB, the required numerical characteristics were calculated and an analysis of the results was completed. In Tab. 2, an overview of linear scales $\mathrm{n}$ (parallels) and $\mathrm{m}$ (meridians) as variables in the Lambert conformal conic projection is given.

Table 2 Linear scales in the variants of the Lambert conformal conic projection

\begin{tabular}{|c|c|c|c|c|c|c|c|c|c|c|}
\hline \multirow{5}{*}{$\varphi$} & \multicolumn{10}{|c|}{ V A R I A N T S of the Lambert conformal conic projection } \\
\hline & \multicolumn{2}{|c|}{1} & \multicolumn{2}{|c|}{ II } & \multicolumn{2}{|c|}{ III } & \multicolumn{2}{|c|}{ IV } & \multicolumn{2}{|c|}{$\mathrm{V}$} \\
\hline & \multirow{2}{*}{\multicolumn{2}{|c|}{$n_{0}=\min =1$}} & \multirow{2}{*}{\multicolumn{2}{|c|}{$\frac{n_{S}=n_{N}}{\varphi_{0}>46^{\circ}}$}} & \multirow{2}{*}{\multicolumn{2}{|c|}{$\begin{array}{c}n_{1}=n_{2}=1 \\
\varphi_{1}=47^{\circ}, \varphi_{2}=45^{\circ}\end{array}$}} & \multirow{2}{*}{\multicolumn{2}{|c|}{$\frac{n_{S}=n_{N}, n_{t}=1}{\varphi_{t}=45^{\circ}}$}} & \multirow{2}{*}{\multicolumn{2}{|c|}{$\begin{array}{c}n_{S}=n_{N}=1+d_{c}, \\
n_{0}=1-d_{c}\end{array}$}} \\
\hline & & & & & & & & & & \\
\hline & $m=n$ & $d_{c}(\%)$ & $m=n$ & $d_{c}(\%)$ & $m=n$ & $d_{c}(\%)$ & $m=n$ & $d_{c}(\%)$ & $m=n$ & $d_{c}(\% \mathrm{o})$ \\
\hline $48^{\circ}$ & 1,000615 & $+0,62$ & 1,000608 & $+0,61$ & 1,000461 & $+0,46$ & 1,000453 & $+0,45$ & 1,000304 & $+0,30$ \\
\hline $47^{\circ}$ & 1,000153 & $+0,15$ & 1,000149 & $+0,15$ & 1,000000 & 0,00 & 0,999994 & $-0,01$ & 0,999845 & $-0,15$ \\
\hline $46^{\circ}$ & 1,000000 & 0,00 & 1,000000 & 0,00 & 0,999848 & $-0,15$ & 0,999845 & $-0,15$ & 0,999696 & $-0,30$ \\
\hline $45^{\circ}$ & 1,000151 & $+0,15$ & 1,000155 & $+0,15$ & 1,000000 & 0,00 & 1,000000 & 0,00 & 0,999851 & $-0,15$ \\
\hline $44^{\circ}$ & 1,000600 & $+0,60$ & 1,000608 & $+0,61$ & 1,000450 & $+0,45$ & 1,000453 & $+0,45$ & 1,000304 & $+0,30$ \\
\hline
\end{tabular}

Obviously the greatest deformations are in the projections with one standard parallel, this being the end parallel. The deformations are $+0,62 \%$ with the I variant and $+0,61 \%$ with the II variant, which is much more favourable than the I variant (Tab. 2).

In projections with two standard parallels, the absolute value of the deformation is a little smaller, which is understandable, and the deformations in the III variant are the greatest, namely 4,6\%. However, in this version, it is possible to choose the area in which we are to set standard parallels with zero deformation in advance if required. A slightly greater deformation, $+0,45 \%$, with nearly the same placing, is in the IV variant, in which we chose one standard parallel in advance.

The smallest absolute values of the deformations, with the appropriate even placings for the whole area of mapping, monitor the $\mathrm{V}$ variant. The absolute values of the deformations are the same in the middle parallel and at the end parallels, namely $\pm 0,30 \%$. Thus, the fifth variant is the most favourable as a matter of size and placing of the deformations on the mapping area.

The Modified polyconic projection is a conditional projection and contains practically all types of deformations (linear, angular and surface deformations).

Table 3 Deformations of the Modified polyconic projection

\begin{tabular}{|c|c|c|c|c|}
\hline \multirow{2}{*}{$\begin{array}{c}\text { IWM 1000 - } \\
\text { sheet Belgrade }\end{array}$} & $\begin{array}{c}\text { Scale } \mathrm{M}_{0} \\
(m)\end{array}$ & $\begin{array}{c}\text { Scale } \mathrm{N}_{0} \\
(n)\end{array}$ & $\begin{array}{c}\text { Angle deformation } \\
(\omega)\end{array}$ & $\begin{array}{c}\text { Surface deformation } \\
\left(p=c^{2}\right)\end{array}$ \\
\cline { 2 - 5 } & 0,999705 & 0,999390 & $32 ", 424$ & 0,999096 \\
\hline
\end{tabular}

For the Belgrade sheet, they are shown in Tab. 3 . According to the calculated linear scales (Tabs. 2 and 3) deformations of the Lambert conformal conic projection

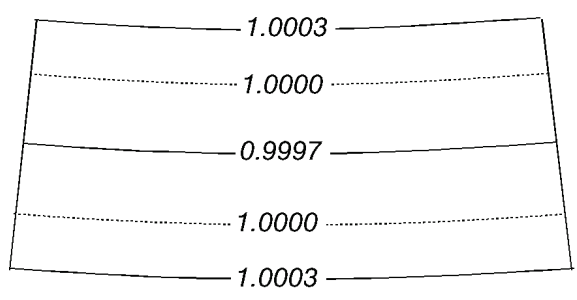

The Lambert conformal conic projection Diagram 1 Preview of the linear proportions on the IMW 1000 in different projections with two standard parallels and of the Modified polyconic projections can be graphically displayed as follows (Fig. 4).

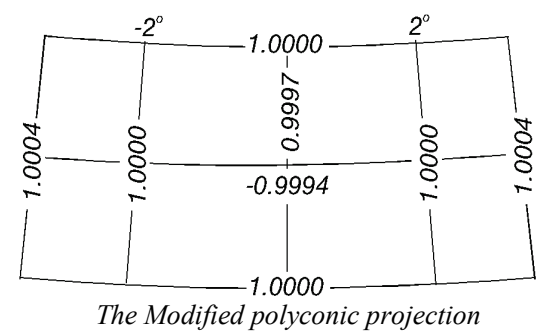

need for smaller deformations in the middle or in any other part of the geographic area being mapped, also affects the quality of the mapping.

Given that all map projections provoke inevitable deformations in length, angles and areas, it is possible to realise the mapping of the surface where some of these 
deformations are eliminated. However, the linear deformations are always present, meaning that a general measure of quality must include linear deformations upon the entire area of mapping.

\section{Review and analysis of the results}

The calculated deformations on the map projection show the difference between the lengths on the ellipsoid and on the plane of projection. They are shown with the aid of linear scales, i.e. with the deformation parameters. Because the given conic map projection is conformal, it has kept the similarity of arbitrarily small figures. This means that the angles have been preserved and that the linear scale in a given point does not depend on direction, but on geographic width. The parameters of the chosen conformal conic map projection (Fig. 5) are:

- Mapping territory:

Serbia and its immediate geographic environment;

- Boundary parallels: $41^{\circ} 30^{\prime} 46^{\circ} 30^{\prime}$;

- Boundary meridians: $18^{\circ} 00^{\prime} 24^{\circ} 00^{\prime}$; and

- Number of crossing points: 49.

The greatest value of linear scales is on the boundary parallels and equals $c_{N}=c_{S}=1,000475$, and the smallest is on the parallel $\varphi_{1}=44^{\circ} 01^{\prime} 04^{\prime \prime}$ and is the same as on $c_{0}$ $=0,999525$. It shows that the deformations are equal and symmetrical to one another in regard to the "middle" parallel on the mapping territory, i.e. to the one where the value of the linear scale is the smallest, namely $c_{N}-1=1$
$-c_{0}=c_{S}-1$, meaning that the quality indicators of map projections are (Tab. 4) as follows.

- Minimal linear scale (deformation): 0,999 $525(-0,000475)$;

- Maximal linear scale (deformation): 1,000475 (0,000 475);

- Maximal relative change in the scale (in \%): $0,094909 \%$; and

- Bandwidth of the linear deformation changes: 0,000945

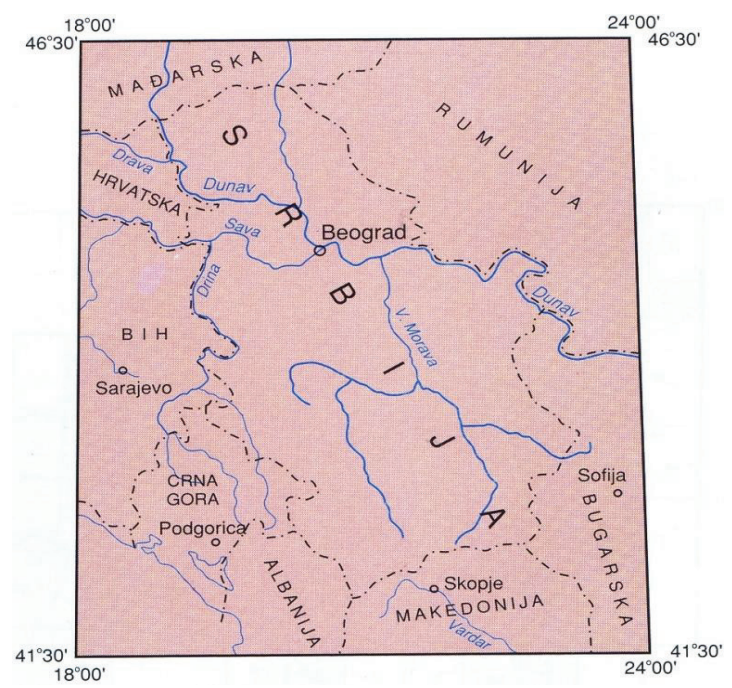

Figure 5 The geographic territory of Serbia for mapping

Table 4 Arrangement of linear scales

\begin{tabular}{|c|c|c|c|c|c|c|c|}
\hline & $18^{\circ}$ & $19^{\circ}$ & $20^{\circ}$ & & 20 & ר & 0 \\
\hline $46^{\circ} 30^{\prime}$ & 1.000475 & 1.000475 & 1.000475 & 1.000475 & 1000475 & 1000475 & 1000475 \\
\hline $46^{\circ}$ & 1,000129 & 1,000129 & 1,000129 & 1,000129 & 1,000129 & 1,000129 & 1,000129 \\
\hline $45^{\circ} 46^{\prime} 38^{\prime \prime}$ & 1,000000 & 1,000000 & 1,000000 & 1,000000 & 1,000000 & 1,000000 & 1,000000 \\
\hline $45^{\circ}$ & 0,999673 & 0,999673 & 0,999673 & 0,999673 & 0,999673 & 0,999673 & 0,999673 \\
\hline $44^{\circ} 01^{\prime} 04^{\prime \prime}$ & 0,999525 & 0,999525 & 0,999525 & 0,999525 & 0,999525 & 0,999525 & 0,999525 \\
\hline $44^{\circ}$ & 0,999526 & 0,999526 & 0,999526 & 0,999526 & 0,999526 & 0,999526 & 0,999526 \\
\hline $43^{\circ}$ & 0,999682 & 0,999682 & 0,999682 & 0,999682 & 0,999682 & 0,999682 & 0,999682 \\
\hline $42^{\circ} 14^{\prime} 26^{\prime \prime}$ & 1,000000 & 1,000000 & 1,000000 & 1,000000 & 1,000000 & 1,000000 & 1,000000 \\
\hline $42^{\circ}$ & 1,000137 & 1,000137 & 1,000137 & 1,000137 & 1,000137 & 1,000137 & 1,000137 \\
\hline $41^{\circ} 30^{\prime}$ & 1,000475 & 1,000475 & 1,000475 & 1,000475 & 1,000475 & 1,000475 & 1,000475 \\
\hline
\end{tabular}

The geographical widths of standard parallels of projections where the linear scale is $c=1$ refer to $\varphi_{1}=42^{\circ}$ $14^{\prime} 26^{\prime \prime}$ and $\varphi_{2}=45^{\circ} 46^{\prime} 38^{\prime \prime}$. The value of the angle deformation is $\omega=0^{\circ}$, and the value of the surface deformation is $p=c^{2}=1000949$. The maximal value of linear deformations is $1000475\left(5 \times 10^{-4}\right)$, i.e. $5 \mathrm{dm}$ on 1 $\mathrm{km}(\sim 0,5 \%)$, which means that a distance of $100 \mathrm{~km}$ measured along the parallels $\left(\varphi_{N}, \varphi_{S}, \varphi_{0}\right)$, is, due to the model of projection, deformed to a degree of $0,05 \mathrm{~mm}$ within the scale of the map.

The ellipses of deformation become circles in this projection, because it deals with conformal mapping, in which the scales around a point have the same values $(m=n)$ in all directions. The smallest radius is that of the ellipse, or circle, on the parallel with the minimal linear scale $\left(n_{0}\right)$. On standard parallels, with widths $\varphi_{1}$ and $\varphi_{2}$, the radii are equal to the unit, and during their moving away in the direction of the north and the south, they increase and decrease, one along with the other.

\section{Conclusion}

Up to this point in time, different kinds of conic projections were used in the making of geographic maps. One of the problems with this approach is the application of old fashioned and inappropriate parameters of cartographic mapping in official cartography. This can be noticed by observing the current state topographic and geographic maps at scales 1:500 000, 1:1000 000 and $1: 1500000$, where many of the parameters of mathematical mapping for the territory of Serbia were taken over from previous cartographic projects.

From a theoretical point of view, no geographic map can be completely trusted and accurate, if only because it represents the doubly curved surface of the ellipsoid on a plane [11]. Therefore, there is no map projection that would ensure the full depiction of shapes and dimensions upon the Earth's surface. Cartographic experts simply have to choose the kind of mapping that is the most suited 
to a particular purpose, or the deformation of which least damages its aim.

In selecting and defining the parameters for an optimal map projection, account was taken of:

- The projection of the map that needs to be from a group of conformal cartographic projections;

- The geographic position and shape of the territory being mapped;

- The linear deformations that need to be minimised, so that along with their minimisation the surface deformations are also $\left(p=c^{2}\right)$; and

- The typisation of the system of official maps, where the term typisation denotes the maintenance of projections in a series of maps, which would make it easy to use and maintain shared geographic content.

Keeping in mind the weaknesses of map projections used previously and aiming for certain changes in a geographic sense, a new kind of conic map projection is proposed. That is the Lambert conformal conic projection with two standard parallels (the fifth variant). On the basis of analysed and newly obtained results, an estimate can be made pertaining to the smallest possible linear deformations in variants of the conformal conic projections for Serbia. For the geographic territory of Serbia, a conformal map projection with smaller deformations is not to be expected. Of course, this is only estimation. However, the balance between deformations and criterion values that fits into the international projection coordinate system is shown on the current geographical mapping territory.

\section{Acknowledgements}

This work was supported by the Ministry of Education, Science and Technological Development, Government of the Republic of Serbia (project No. 176018).

\section{References}

[1] Bugayevskiy, L.; Snyder, J. Map Projections, A Reference Manual, UK, 1998.

[2] Grafarend, E.; Krumm, F. Map Projections, Cartographic Information Systems, Springer US, 2006.

[3] Monografija. Geodetska delatnost u Srbiji 1837.-2012., Republički Geodetski Zavod, Beograd, 2012.

[4] Sample, J.; Loup, E. Map Projections, Tile-Based Geospatial Information Systems, Springer US, 2010. DOI: 10.1007/978-1-4419-7631-4_10

[5] Tutić, D. Konformne projekcije za Hrvatsku s najmanjim apsolutnim linearnim deformacijama. // Geodetski list, Br. 3, (2010), pp. 157-173.

[6] Robinson, A.; Morrison, J.; Muehrcke, P.; Kimerling, A.; Guptill, S. Elements of Cartography, Sixth Edition, USA, 1995.

[7] Manual for cartographic publications in Serbian. URL: http://www.vgi.mod.gov.rs/english/product/publishing.html (15.02.2014.).

[8] UN Technical Conference on the International Map of the World on the Milionith Scale, Specifications of the International Map of the World on the Milionith Scale, Bon 1962, New York 1963.

[9] Defence Imagery and Geospatial Organisation. URL:
http://www.defence.gov.au/digo/Products/products.html, (17.02.2014.).

[10] Annoni, A.; Luzet, C.; Gubler, E. and Ihde, J. Map Projections for Europe, Institute for Environment and Sustainability, Italy, 2003.

[11] Brainerd, J.; Pang, A. Interactive map projections and distortion. // Computers and Geosciences. 27, (2001), pp. 299-314. DOI: 10.1016/S0098-3004(00)00108-4

[12] ESRI. Understanding Map Projections, GIS by ESRI, Redlands, USA, 2004.

[13] Frančula, N. Kartografske projekcije, Skripta, Geodetski fakultet Sveučilišta u Zagrebu, Croatia, 2001.

[14] Jovanović, V. Matematička kartografija, Naučna knjiga, Beograd, 1983.

[15] Govedarica, M.; Borisov, M. The analyses of data quality on topographic maps. // Geodetski vestnik. 55, 4(2011), pp. 713-725. DOI: 10.15292/geodetski-vestnik.2011.04.713-725

\section{Authors' addresses}

Ph.D. Mirko Borisov

Faculty of Technical Sciences University of Novi Sad Trg Dositej Obradović 6, 21000 Novi Sad, Republic of Serbia E-mail: mirkoborisov@gmail.com

\section{M.Sc. Vladimir M. Petrović}

University of Belgrade, Institute of Chemistry, Technology and Metallurgy, Department for Ecology and Technoeconomics Njegoševa 12, 11000 Belgrade, Republic of Serbia E-mail: vladimirpetrovic.gis@gmail.com

\section{Ph.D. Milivoj Vulić}

Faculty of Natural Sciences and Engineering Chair for Mine Surveying and Applied Geophysics University of Ljubljana Aškerčeva 12, 1000 Ljubljana, Republic of Slovenia E-mail: milivoj.vulic@guest.arnes.si 